\title{
Oralidade, ensino de língua portuguesa e formação do professor
}

\section{Orality, teaching Portuguese language and teacher training}

\author{
Sandoval Nonato* \\ *Universidade de São Paulo (USP) São Paulo, São Paulo / Brasil \\ sandovalnonato@gmail.com
}

https://orcid.org/0000-0002-3976-584X

RESUMO: Este estudo propõe discutir o estatuto da oralidade como componente curricular da disciplina língua portuguesa na escola brasileira. Para tanto, apresenta-se, inicialmente, um panorama dos modos com que a oralidade é abordada no percurso histórico de constituição do ensino de língua portuguesa, no que se refere aos currículos e programas de ensino e aos materiais didáticos propostos. Em seguida, contrasta-se esse estatuto historicamente construído da oralidade com práticas de ensino de língua portuguesa atuais mediadas por estudantes de licenciatura em Letras, por ocasião de realização de estágio em escolas da rede pública da cidade de São Paulo (Brasil). A descrição e a análise do processo de implementação de um projeto de ensino do gênero textual debate oral por uma estudante, conforme registrado em seu relatório de estágio, permitem problematizar alguns desafios que a abordagem da oralidade coloca para as práticas de ensino e para a formação do professor de língua portuguesa.

PALAVRAS-CHAVE: Ensino de língua portuguesa; formação docente; gênero textual; oralidade; relatório de estágio.

ABSTRACT: This study proposes to discuss the status of orality as a curricular component of the subject Portuguese language in the Brazilian school. Therefore, it presents, initially, an overview of the ways in which orality is approached in the historical course of the constitution of Portuguese language teaching, in what it refers to the curricula and teaching programs and the didactic materials proposed. Next, this historically constructed status of orality is contrasted with current Portuguese language teaching practices mediated by students for licentiate in Letters, on the occasion of an internship in schools of the public system of the city of São Paulo (Brazil). The description and analysis of the process of implementation of a teaching project about oral debate as a textual genre by a student, as recorded in your internship report, allow us to problematize some of the challenges that the orality approach poses to teaching practices and to the training of the Portuguese language teacher.

KEYWORDS: Teaching Portuguese language; reacher training; textual genre; orality; internship report. 


\section{Introdução}

Tratar da oralidade como saber escolar ou conteúdo de ensino de língua portuguesa é abordar um componente curricular presente na história desse ensino desde sua gênese, ainda em meados do século XIX, quando a disciplina língua portuguesa vai se oficializando nos programas e currículos da nascente escolarização formal no Brasil. Estudos sobre a história do ensino de língua portuguesa traçam o percurso pelo qual a linguagem oral vai sendo moldada como objeto de ensino com base em saberes sobre os usos da palavra; mais especificamente, sobre o uso retórico da palavra, sobre a técnica ou arte da elocução, da oratória, da eloquência, eco da cultura beletrista e clássica que marca os primeiros passos da disciplina língua portuguesa rumo à sua consolidação nos estabelecimentos de ensino brasileiros, tendo por instituição fundadora o Colégio Pedro II, criado em 1838, no Rio de Janeiro (cf. BUNZEN, 2011; PIETRI, 2010; RAZZINI, 2000; ROJO, 2008; SOARES, 1997, 2002).

Quanto à linguagem oral como objeto de ensino, frequentam os planos de ensino do Colégio tópicos de conteúdo relativos à divisão clássica dos gêneros oratórios e poéticos, estilos, figuras e tropos retóricos, partes do discurso, gêneros de eloquência etc. Em uma palavra, tópicos de conteúdo que conformam um discurso expositivo sobre um saber de natureza procedimental consubstanciado na técnica ou na arte de falar em público. No prefácio de seu $A$ arte de falar em público, publicado em 1933, o professor Silveira Bueno enfatiza a necessidade de instigar nos bancos escolares os estudos de Retórica,

a arte que regulariza, ordena e aperfeiçoa a natural disposição de quem nasceu eloquente. Muitos que assim apareceram dotados pelo berço, nunca puderam desenvolver as suas qualidades de orador porque jamais encontraram as regras, os meios, os adminículos próprios para tal desenvolvimento. Desta forma, perderam o magnífico presente dos deuses (BUENO, 1945, p. 9).

Com base nas considerações arroladas, proponho, neste estudo, caracterizar o estatuto da oralidade como componente curricular da disciplina língua portuguesa na escola brasileira. Para tanto, apresento, inicialmente, um panorama dos modos com que a oralidade é abordada no percurso histórico de constituição do ensino de língua portuguesa, no que se refere aos currículos e programas de ensino e aos materiais didáticos 
propostos. Em seguida, busco contrastar esse estatuto historicamente construído da oralidade com práticas de ensino de língua portuguesa atuais.

\section{Oralidade e ensino de língua portuguesa: modelo clássico e vocação beletrista}

Cotejando os programas de ensino do Colégio Pedro II com os materiais didáticos utilizados e os documentos oficiais em que ambos se ancoram, o estudo de Razzini (2000) traça uma cronologia robusta do percurso de invenção histórica da disciplina escolar Português em um intervalo de quase um século e meio, entre 1838 e 1971. Ao longo de toda a primeira metade do século passado, exercícios de recitação e de leitura expressiva (de textos de poetas e prosadores) ou de leitura em voz alta, bem como aqueles de composição oral (declamação, composição livre, exercícios de "boa dicção" etc.) são instrumentos didáticos centrais do professor de língua portuguesa para tornar presente e fazer circular o saber sobre oralidade na sala de aula.

A esses instrumentos associam-se estreitamente aqueles que dão a base material ao saber escolar sobre oralidade, ou seja, as coletâneas, seletas ou antologias de textos (em gêneros poéticos e retóricos clássicos e também em gêneros em prosa - memórias, discursos, biografias etc.) de autores considerados modelos de bem falare bem escrever (prosadores e poetas da cultura greco-latina, em um primeiro momento, passando pelos poetas, escritores e oradores lusitanos, até chegar aos autores brasileiros e se fixar preferencialmente neles).

Nesses materiais, bem como nos compêndios e nos manuais didáticos destinados ao ensino de língua portuguesa até as décadas de 1960 e 1970, os textos vão sendo selecionados e organizados conforme uma classificação em gêneros poéticos e em prosa - poesia, conto, discursos, biografias, cartas etc. - e ainda conforme tipologias textuais (narrações, descrições, dissertações, enumerações, exposições). Sobre tais textos, que vão compondo ao longo do tempo uma espécie de cânon textual escolar, incidem as atividades escolares propostas e as tarefas formuladas aos alunos.

A vocalização ou elocução desses textos tem pelo menos três funções didáticas, a saber: 
i) o treino da pronúncia, da dicção e da fluência em leitura, sobretudo em se tratando dos anos iniciais de escolarização;

ii) a fixação dos temas ou assuntos dos textos (por exemplo, temas de natureza patriótica ou moral que buscam contribuir para a construção de uma identidade nacional brasileira e de um caráter para o cidadão brasileiro);

iii) a incorporação de modos de dizer considerados claros, corretos e elegantes, emprestados a autores renomados, em textos de diferentes tipos e gêneros.

Vejamos como parte dessas funções da oralidade aparece nos comentários e nas recomendações feitos pelo professor Júlio Nogueira em seu manual intitulado A linguagem usual e a composição, publicado em 1929. No capítulo $A$ composição oral, após fazer um "apello a todo o professorado do nosso paiz para que adopte este methodo de tão felizes resultados" (NOGUEIRA, 1929, p. 313), tendo em vista a necessidade de incentivar “...a pratica de falar em publico, a confiança nos recursos proprios de expressão, a qual só o exercício póde dar” (NOGUEIRA, 1929, p. 314), ${ }^{1}$ o professor apresenta seu método de ensino que inclui dois grupos de "exercícios de elocução que se podem fazer nos cursos de língua portuguesa e de literatura, uma vez que a rhetorica já desappareceu do ensino" (NOGUEIRA, 1929, p. 314-315): ${ }^{2}$

- exercícios mais simples ou "precedentes":

- paráfrase de um caso simples, uma anedota ou notícia de jornal;

- leitura de uma produção poética e resumo do que se leu;

- versão de frases do francês para o português.

\footnotetext{
${ }^{1} \mathrm{Na}$ transcrição de excertos da obra em tela, manteve-se a grafia do original.

${ }^{2}$ É curioso notar que o sentido desse apelo vai ao encontro de um discurso que denuncia o depauperamento progressivo dos estudos retóricos no currículo de língua portuguesa, já no início do século XX, o que revela o estágio de consolidação do Português como disciplina autônoma e aponta os contornos que adquirirá por toda a primeira metade do século. Nos termos de Nogueira, "A oratória tem perdido muito do apreço em que era tida. A época dos discursos que inflammavam as multidões passou com os factos históricos que lhes davam origem. Os poucos oradores que nos restam ainda vão buscar no passado o motivo de seus discursos. Os oradores politicos já não fazem discursos: discutem apenas e por vezes com um desalinho de linguagem que em nada os recommenda. Um organizador de anthologia oratoria, além de Ruy Barbosa, pouco teria que respigar nos annaes do nosso parlamento." (NOGUEIRA, 1929, p. 314).
} 
- exercícios avançados, "em que a individualidade do narrador se afirma de maneira mais positiva":

- narração de um acidente;

- resumo de entrecho de filme ou peça teatral;

- síntese de um romance;

- relatório verbal de uma sessão de que se participou;

- descrição de um passeio, de uma festa cívica, escolar ou religiosa;

- opinião sobre ideias discutidas na imprensa ou no parlamento;

- discussão em torno de um "thema social";

- comentário de livros lidos;

- pequenos discursos em torno de temas e situações diversas ("festas escolares ou familiares; brindes por ocasião de anniversario..."). (NOGUEIRA, 1929, p. 315-316).

Essa ampla lista de exercícios encontra sua justificativa na finalidade de formação das gerações de jovens para o exercício público da linguagem oral. Nas palavras de Julio Nogueira:

Esses e outros exercícios, que hão de desenvolver consideravelmente a capacidade dos nossos jovens para o uso da palavra, prepararão decerto gerações melhores de homens públicos, que saibam exprimir-se com clareza, correcção e até com a discreta elegancia que a todos empolga. $\mathrm{O}$ homem que fala bem, seja na conversação vulgar, seja em tom oratório, impõe-se á consideração de todos. É mais facil encontrar leaders entre os oradores de turmas que entre os bisonhos colegas que apenas os applaudiam. Não esqueçamos que falar bem, expor o pensamento ou opinião sem esforço nem repetições ociosas, prender a attenção de todos constitue já a melhor das recomendações. Não se confunda essa faculdade com o falar precioso, rebuscado de alguns, o chamado falar difícil, que irrita em vez de agradar. (NOGUEIRA, 1929, p. 317).

Não é demais lembrar que, na conjuntura histórica brasileira dos anos 1920, 1930 e de toda a metade do século passado, a escolarização não alcança sequer uma parcela mínima da população: assim, tanto os "oradores de turmas", os futuros leaders, quanto os "bisonhos colegas que apenas os applaudiam" não representam senão uma parcela privilegiada da elite urbana brasileira que tem acesso ao letramento escolar. O saber escolar sobre oralidade ou o uso da linguagem oral na escola serve, portanto, não apenas para instrução daqueles que têm acesso à escola, mas também para 
sua socialização conforme a finalidade de distinção e conservação tanto do repertório ou capital cultural legítimo, quanto das posições sociais legitimadas para transformá-lo em palavra pública.

Esse estatuto em que é investida a oralidade remete ao empreendimento considerado civilizatório de invenção, pela mediação da forma escolar (LAHIRE, 2008), do homem brasileiro moderno e urbano, capaz de participar da vida pública pelo voto (cf. BOTO, 2003; FARIA-FILHO, 2005). Mais especificamente, tal estatuto alinha-se ao modelo clássico e à vocação beletrista em que se constitui o ensino de língua portuguesa, com nuanças particulares, desde sua gênese até meados do século passado.

O modelo clássico e essa vocação beletrista passam a ser tensionados a partir dos anos 1960 e ao longo dos anos 1970, com a ampliação de acesso da população à escola e consequente mudança do perfil do alunado, bem como pela intensificação do processo de depreciação e precarização do trabalho docente. ${ }^{3}$ Desde então, será necessário aguardar mais de vinte anos para que uma virada pudesse ser assinalada no percurso de constituição do ensino de língua portuguesa e, mais particularmente, no percurso de instanciação da oralidade como componente curricular desse ensino, o que toma lugar a partir dos anos 1980, conforme veremos a seguir.

\section{A oralidade revisitada}

Passado um século e meio de construção dessa tradição de abordagem da linguagem oral no ensino de língua portuguesa, começa a se desenhar um ponto de inflexão no tratamento da oralidade a partir dos anos 1980, na conjuntura de construção de uma nova perspectiva para o ensino de língua portuguesa. Lugar central no processo de reconfiguração curricular, nessa conjuntura, é assumido por aportes teóricos do campo dos estudos da linguagem - estudos do texto e do discurso e estudos em linguística aplicada -, entre outros, que tornam mais inteligíveis as implicações epistemológicas de uma concepção de linguagem como ação e de ensino como incorporação ou apropriação de saberes e práticas socioculturalmente

\footnotetext{
${ }^{3}$ A promulgação da Lei de Diretrizes e Bases da Educação - Lei no 5.692/71 (BRASIL, 1971) - oficializa um conjunto de novas finalidades colocadas para a escola e para o ensino de língua portuguesa na conjuntura social, política e econômica do Brasil dos anos de regime militar. Com a mudança das finalidades, alteram-se o corpo de saberes e o conjunto de dispositivos de sua distribuição e seu consumo.
} 
condicionados, pedra de toque da inovação curricular (PIETRI, 2003) que se busca propõe construir.

$\mathrm{Na}$ esteira desse processo, os Parâmetros Curriculares Nacionais (PCN) de Língua Portuguesa para o Ensino Fundamental (BRASIL, 1998) elegem os gêneros textuais como objetos de ensino. A seleção da coletânea de textos para o trabalho didático é delimitada por quatro campos sociais de produção discursiva - divulgação científica, imprensa, cultura literária e publicidade, sendo considerados textos escritos e orais. Tornar mais visível e didaticamente sistemática a abordagem do texto (incluído o texto oral) como unidade de ensino das práticas didáticas está entre as contribuições do processo de implementação curricular alavancado pela publicação dos PCN (cf. GOMES-SANTOS, 2004). ${ }^{4}$

Nesse novo modelo que se desenha para o ensino de língua portuguesa, a oralidade vai adquirindo um estatuto autônomo com relação aos outros componentes curriculares, o que exige, do ponto de vista didático, a proposição de um conjunto de objetos de ensino ou conteúdos e de métodos de ensino a ela concernentes. No que se refere aos objetos de ensino ou conteúdos, selecionam-se saberes relativos aos modos de funcionamento sociodiscursivo e de organização textual e aos recursos linguísticos de:

$\checkmark$ gêneros orais (formais e públicos) como o debate, a assembleia e a exposição oral, incluídos os recursos textuais (linguísticos) que permitem sua produção (recurso de exemplificação, por exemplo, no caso das exposições orais, ou recurso de citação de discurso de autoridade, no caso do debate);

$\checkmark$ gêneros textuais em que a oralidade é representada ou estilizada pela escrita, como aqueles da cultura popular ou oral: cordel, mitos, provérbios e lendas;

\footnotetext{
${ }^{4}$ É no contexto de proposição de novo modelo para o ensino de língua portuguesa que emerge a indicação de L. A. Marcuschi (MARCUSCHI, 2001) com relação ao silenciamento sobre o lugar e o papel da oralidade no ensino de língua portuguesa: para ele, trata-se de "uma questão pouco falada". Analisando um conjunto de livros didáticos de língua portuguesa para o Ensino Fundamental, o professor sintetiza as tendências de tratamento dispensado à oralidade nesses manuais, entre as quais a "oscilação terminológica" e o "privilégio às atividades de oralização da escrita".
} 
$\checkmark$ gêneros textuais em que a oralidade aparece estreitamente combinada com a escrita e com outros sistemas semióticos (imagens fixas ou animadas, gestos, cores, sons etc.), como ocorre com os gêneros das mídias impressa, televisiva e digital (HQs, programas televisivos, vídeos, jogos digitais, gifs, memes, podcasts, filmes de animação etc.).

Já no que respeita aos métodos de ensino, propõe-se que a abordagem da oralidade ocorra no seio de práticas de recepção e produção que reencontrem e ampliem as experiências e os repertórios culturais dos indivíduos que chegam à escola. Figura desse esforço é a necessidade que adquire o princípio de contextualização do saber pela proposição de percursos de ensino e de aprendizagem orgânicos e mais ou menos flexíveis, em sequências ou projetos didáticos.

O que está fundamentalmente em jogo nessa reconfiguração do estatuto da oralidade no currículo de língua portuguesa, na conjuntura em questão, é, como observa Rojo (2008), um movimento de retorno ou de atualização de uma perspectiva retórica no ensino de língua portuguesa eivado que ainda se encontra, na conjuntura em questão, por tópicos de conteúdo de natureza gramatical, o capital cultural por excelência que traduz a identidade da disciplina ao longo de sua história. Poderíamos falar em um processo de retoricização do currículo com base na centralidade das práticas de recepção e produção de textos (ou, em outros termos, dos usos retóricos da palavra) como o princípio gerador dos objetos e catalisador dos instrumentos de ensino.

Não se trataria, por óbvio, de retomada automática nem mecânica de um corpo de saberes ou de procedimentos de ensino diluídos em uma difusa tradição escolar, mas do alçamento de um modo de consumo e de produção do capital cultural que poderia ser aproximado a uma racionalidade retórica, no sentido em que a definem Perelman e Olbrechts-Tyteca (2005, p. 132) em seu tratado de argumentação. Essa racionalidade tem como um de seus princípios geradores a seleção e a instanciação da presença material e simbólica do capital cultural em jogo, o que a distinguiria da racionalidade fundada em concepções racionalistas do raciocínio, hegemônicas na história da forma escolar e no ensino de língua portuguesa.

A consideração desta dupla dimensão estruturante do trabalho de ensino da oralidade - saber e método de ensino - pode subsidiar a compreensão de como lógicas ou concepções construídas na tradição de ensino de língua portuguesa produzem efeitos em práticas atuais de ensino 
da oralidade, particularmente naquelas mediadas por futuros professores de língua portuguesa, licenciandos em processo de formação acadêmica, por ocasião de realização de estágio de regência em escolas da rede pública de ensino de São Paulo (SP, Brasil), como são as de que tratamos na próxima seção.

\section{Oralidade e formação do professor de língua portuguesa}

Nesta seção, procuro ilustrar o conjunto de considerações apresentadas pelo recurso a registro escrito de práticas de ensino conforme representadas em um relatório de estágio elaborado como produto final do Curso de Metodologia de Ensino do Português/2 (EDM 0406), por uma estudante do Curso de Licenciatura em Letras da Faculdade de Educação da Universidade de São Paulo. ${ }^{5}$ Com base nesse registro, proponho interpretar o processo de implementação de um projeto de ensino do debate oral.

O relatório selecionado ${ }^{6}$ para a discussão proposta nesta seção enfoca um projeto de ensino implementado em uma turma de $7^{\circ}$ ano do Ensino Fundamental. O Quadro 1, abaixo, condensa dados de identificação do projeto de ensino, além daqueles relativos aos objetos ensinados e aos instrumentos didáticos (incluída a coletânea de textos) usados em sua implementação.

\footnotetext{
${ }^{5}$ Como têm mostrado diversos estudos sobre a formação do professor de língua portuguesa (cf. GOMES-SANTOS; SEIXAS, 2012; SILVA, 2013; SILVA; MELO, 2008), a consideração deste artefato material da prática de formação profissional, o relatório de estágio, pode trazer múltiplos indícios de questões, problemas e desafios que o processo de atualização dos saberes e métodos de ensino da disciplina língua portuguesa coloca para o professor em formação.

${ }^{6}$ Os dados considerados neste estudo integram o corpus do Projeto de Pesquisa Formação inicial e letramento do professor de lingua portuguesa: conceber, implementar e avaliar projetos de ensino (GOMES-SANTOS, 2016-2019). Tal corpus, por sua vez, integra um banco de dados mais amplo, em processo de catalogação, que comporta aproximadamente quinhentos relatórios de estágio. A seleção do relatório em tela neste estudo considerou: i) o componente curricular nele focalizado (a oralidade); ii) a forte aderência da descrição e da análise nele ensejadas para a discussão proposta neste estudo e iii) a supervisão explícita que procedi, na condição de professor, de seu processo de produção.
} 
QUADRO 1 - Dados do relatório selecionado

\begin{tabular}{|c|c|}
\hline De & $\begin{array}{l}\text { O gênero debate em uma turma de } 7^{\circ} \text { ano de escola pública: } \\
\text { alcances e desafios }\end{array}$ \\
\hline $\begin{array}{l}\text { Escola, } \\
\text { ensino }\end{array}$ & $\begin{array}{l}\text { Escola estadual, localizada no bairro do Rio Pequeno, subdistrito do } \\
\text { Butantã, na Zona Oeste de São Paulo (SP) } \\
7^{\circ} \text { ano do Ensino Fundamental }\end{array}$ \\
\hline Objetos en & $\begin{array}{l}\text { Debate oral re"grado: } \\
\text { > Tema: expulsão de alunos } \\
\text { > Sequência textual argumentativa } \\
\text { > Organização composicional e funcionamento do debate } \\
\text { > Recursos de construção das relações entre causa e efeito, tese e } \\
\quad \text { premissa; recursos de contra-argumentação. }\end{array}$ \\
\hline $\mathrm{Col}$ & $\begin{array}{l}\checkmark \text { Notícia: Norma prevê que escolas do Estado não possam mais expulsar } \\
\quad \text { alunos } \\
\checkmark \text { Artigo de opinião: Aluno indisciplinado não pode ser expulso } \\
\checkmark \text { Artigo de opinião: Expulsar para manter a disciplina nas escolas } \\
\checkmark \text { Vídeo: debate presidencial } 2014-1^{\circ} \text { bloco }-2^{\circ} \text { turno }- \text { TV Band - } \\
\quad \text { 14/10/2014 - HD } \\
\checkmark \text { Vídeo: Campanha Política (2014), da Cia. Barbixas de Humor } \\
\checkmark \text { Texto expositivo escrito com compilação de argumentos gerados em } \\
\quad \text { sala de aula }\end{array}$ \\
\hline $\begin{array}{l}\text { Instrumentos } \\
\text { didáticos }\end{array}$ & $\begin{array}{l}\text { - Leitura oral compartilhada seguida de discussão sobre os textos } \\
\text { - Jogo: simulação de venda de um objeto (grampeador), com registro dos } \\
\text { argumentos dos alunos na lousa } \\
\text { - Produção escrita coletiva de uma história fictícia } \\
\text { - Questionário sobre artigos de opinião (4 questões dissertativas) } \\
\text { - Reprodução guiada de vídeos de debates seguida de discussão coletiva } \\
\text { - Exposição oral } \\
\text { - Tarefa em grupo de planejamento do debate } \\
\text { - Tarefa de execução do debate }\end{array}$ \\
\hline
\end{tabular}

Fonte: Elaborado pelo autor com base no banco de dados do Grupo de Pesquisa Linguagem na Prática Escolar - FEUSP.

Vejamos, a seguir, como estes dois ingredientes do projeto de ensino (objetos ensinados e instrumentos didáticos) ${ }^{7}$ ganham corpo nas práticas

\footnotetext{
${ }^{7}$ Para a caracterização do percurso de implementação do projeto de ensino, recorro, na descrição e análise do relatório, à contribuição dos estudos sobre o trabalho docente em uma perspectiva didática desenvolvidos por Bernard Schneuwly, Joaquin Dolz e seus colaboradores (SCHNEUWLY; DOLZ, 2009).
} 
de ensino representadas no relatório, bem como quais os desafios didáticos que o ensino da oralidade coloca para o professor em formação.

\subsection{O debate oral em uma turma de $7^{\circ}$ ano do Ensino Fundamental}

O relatório intitulado $O$ gênero debate em uma turma de $7^{\circ}$ ano de escola pública: alcances e desafios expõe o processo de implementação de um projeto de ensino do gênero textual debate oral junto a alunos do $7^{\circ}$ ano do Ensino Fundamental de uma escola da rede estadual de ensino de São Paulo, adolescentes com idade média de doze anos, em um percurso de 10 (dez) aulas no segundo semestre de 2014.

Esse objeto de ensino debate oral é delimitado pela seleção de tópicos de conteúdo particulares, de natureza tanto temática (o tema expulsão de alunos), quanto configuracional (organização composicional e funcionamento do debate), passando por aqueles de natureza linguísticotextual (recursos de construção das relações de causa e efeito; conceitos de premissa e tese; recursos de contra-argumentação). ${ }^{8}$

A gênese e seleção do tema buscam-se ancorar naquilo que a licencianda representa como experiência social mais imediata aos alunos para os quais o projeto se volta: o tema da expulsão havia se colocado como problema para o grupo a partir de divergências nas relações intersubjetivas em sala de aula, especialmente com a proposição por duas alunas de um abaixo-assinado solicitando a expulsão de um colega da turma, em função de conduta supostamente inadequada dele com relação a elas. A seleção desse tema visa a promover interesse ou engajamento dos alunos no percurso de implementação do projeto de ensino do debate oral.

O tratamento desse tema ancora-se em uma coletânea de três textos escritos (uma notícia e dois artigos de opinião). A coletânea que apoia o tratamento da organização configuracional do debate comporta dois textos multissemióticos (um vídeo de um debate político e outro de uma paródia do mesmo debate). Já os recursos linguístico-textuais são tratados com base no conjunto dos textos. Associado a essa coletânea de textos, um arsenal

\footnotetext{
${ }^{8}$ Essa delimitação tripartite do objeto - em sua dimensão temática, configuracional e linguístico-textual - recupera mutatis mutandis a definição das partes ou dimensões da produção discursiva conforme a tradição retórica, a saber: a inventio (geração dos temas), a dispositio (distribuição dos tópicos temáticos em uma organização composicional global) e elocutio (formulação linguística) (cf. FIORIN, 1999).
} 
diversificado de outros instrumentos didáticos é acionado no percurso de ensino do debate oral.

Entre tais instrumentos, a leitura oral (compartilhada) acompanhada de discussão (coletiva) e o questionário são aqueles que buscam tornar presente em sala de aula o tema do debate e a polêmica nele implicada: pode-se ou deve-se expulsar alunos da escola? A combinação de leitura oral com discussão marca o ponto de partida do percurso didático, assumindo o papel de inserir o tema do debate no meio didático que se instaura e, desse modo, promovendo um primeiro acesso a informações sobre ele pelos alunos, ou seja, repertoriando-os particularmente com relação a elementos temáticos do debate (nos termos de Schneuwly (2009), gesto didático de presentificação do objeto de saber).

Uma ocorrência de reação dos alunos registrada pela licencianda em seu relatório revela a potência dessa combinação de instrumentos no alçamento de outras interpretações para os textos, diferentes daquelas previstas quando do planejamento do projeto. Em seus termos,

Outro aspecto que precisa ser destacado na presente análise foi a interpretação que os alunos fizeram diante dos textos da coletânea que levamos no primeiro dia do projeto. Os estudantes enxergaram o artigo de opinião que defendia a norma (e, portanto, que não era a favor da expulsão) como um texto que defendia os alunos; enquanto que o artigo que era contrário à norma (ou seja, a favor da expulsão), os alunos enxergaram como um defensor da escola. $\mathrm{O}$ interessante nessas interpretações é a polarização feita pela turma: alunos em oposição à escola. Segundo os estudantes, então, expulsar os alunos é um mecanismo que beneficia a escola enquanto que manter os mesmos dentro do espaço escolar é sinônimo de proteção aos estudantes, se assim podemos dizer. Caso o número de aulas tivesse sido maior, teríamos debatido essas interpretações com os alunos, mas não foi possível. No entanto, essa visão já nos denuncia a maneira como os estudantes enxergam a escola: como um espaço onde nem sempre eles se sentem compreendidos. (ALS_Oralidade_2014, p. 16) ${ }^{9}$

Já instrumentos didáticos como a produção coletiva de uma história fictícia (com o objetivo de distinguir sequência textual narrativa de sequência argumentativa) e a reprodução de vídeos acompanhada por exposição

\footnotetext{
${ }^{9}$ A inserção entre colchetes remete à codificação do relatório de estágio considerado, no banco de dados do Grupo de Pesquisa Linguagem na Prática Escolar (LIPRE/FEUSP).
} 
oral ou discussão com o grupo de alunos assumem a função de topicalizar ou desdobrar o objeto de ensino debate oral, seja do ponto de vista de sua organização composicional, seja dos recursos linguístico-textuais de formulação da argumentação (segundo a formulação de Schneuwly (2009), gesto didático de pointage ou topicalização do objeto de saber em seus constituintes).

Além desses, há um curioso registro do uso da simulação como instrumento didático: os alunos são convidados a encenar a venda de um grampeador, sendo seus argumentos registrados na lousa. O uso desse instrumento busca promover o acesso dos alunos ao fim último da ação de argumentar - convencer ou persuadir um auditório -, o principal tópico de conteúdo entre aqueles em que se constitui o debate. Assim é registrada pela licencianda a implementação desse instrumento didático:

[...] uma das atividades propostas foi que os estudantes nos convencessem a comprar um grampeador. Desejávamos aqui que eles fizessem uso de argumentos e que compreendessem a função desse recurso. Gostamos da reação dos alunos diante dessa atividade, pois eles ficaram bastante empolgados com a proposta e se empenharam para que fôssemos convencidas. Essa atividade foi bastante importante porque depois a retomamos várias vezes para que algumas dúvidas que foram aparecendo fossem esclarecidas. A partir dessa atividade, ensinamos os conceitos de premissa, causa e efeito. (ALS_Oralidade_2014, p. 10-11)

Todos esses instrumentos que vão conferindo presença objetiva ao saber sobre o debate oral em sala de aula ao longo do processo de implementação do projeto confluem para a tarefa de planejamento do debate a ser realizado pelos alunos como produto final do percurso didático. Uma ocorrência singular marca a realização dessa tarefa: a distribuição dos alunos em dois grupos com base na oposição entre opinião favorável à expulsão e opinião contrária. A singularidade da ocorrência está no fato de essas opiniões terem se distribuído em dois agrupamentos definidos por gênero antropológico, alunas e alunos, elas favoráveis à expulsão e eles, contrários. Nos termos da licencianda:

Dividimos a sala em dois grupos: um seria a favor da norma e o outro seria contra. A divisão foi feita seguindo a opinião pessoal deles mesmo. Houve uma divisão entre meninos de um lado (a favor da norma) e meninas do outro (contra a norma). Nessa divisão, aconteceu algo curioso: um menino era contra norma, mas diante da divisão dos grupos, 
optou ficar no grupo dos meninos porque não queria ser o único do sexo masculino no grupo das meninas. Não tivemos tempo de discutir essa questão com os alunos, por isso aceitamos a configuração que se estabeleceu. (ALS_Oralidade_2014, p. 12)

Esse modo de ocupação das posições a favor ou contra a expulsão produz efeito na ocasião de execução da tarefa do debate, concorrendo para a emergência de duas performances distintas de uso da linguagem oral: aparentemente, embora não haja maior explicitação dessas performances na descrição do episódio feita no relatório, enquanto os alunos oralizam o textosíntese dos argumentos anteriormente disponibilizado à turma, as alunas buscam produzir uma fala espontânea. ${ }^{10}$

O mais interessante é que esse distinto modo de produção oral leitura oral e fala espontânea - se apoia, consciente ou inconscientemente, nas diferentes implicações que ser a favor ou contrário à expulsão coloca para cada um dos grupos: por parte do grupo de alunos, a leitura oral, apoiada no artefato escrito (impresso), atenua os efeitos de uma performance oral movediça, suscetível ao confronto e, desse modo, auxilia a preservação de suas faces. ${ }^{11}$ Por parte do grupo de alunas, a fala espontânea promove exatamente a vontade de confronto, o posicionamento a favor da expulsão, em continuidade àquele mesmo confronto suposto na proposição de abaixoassinado feito por duas colegas da turma em favor da expulsão de um outro colega:

Outro aspecto que nos chamou atenção foi a apropriação da primeira pessoa do discurso durante o debate: as meninas, que se posicionaram contra a norma (e, portanto, a favor da expulsão), debatiam sem dimensionar que o assunto que estavam debatendo não era uma realidade apenas delas, mas sim de toda e qualquer escola. Os meninos, por outro lado, sentiam-se um pouco recuados porque defendiam um

\footnotetext{
${ }^{10}$ Em seu estudo sobre a conferência, Erving Goffman menciona três maneiras de animar as palavras: a memorização, a leitura oral e a fala espontânea (GOFFMAN, 1987, p. 178).

${ }^{11}$ Ora, para os alunos, ser contrário à expulsão parece se constituir em um posicionamento que deve ser expresso discretamente, sem muito alarde, já que não se trata de posicionamento hegemônico na escola, conforme o que representam de norma instituída e conforme o próprio tipo de pertencimento que estabelecem com relação à instituição, muitas vezes atravessado pela equação escola versus alunos, representação que emerge nas discussões sobre os textos lidos no início da implementação do projeto, conforme mencionado.
} 
posicionamento com que até o professor mostrou discordar. Talvez por conta disso, eles não tenham se sentindo confiantes o suficiente para se expressar. (ALS_Oralidade_2014,p. 14)

Embora o episódio de divisão de grupos por gênero (garotas e garotos) na ocasião da tarefa de planejamento e seus desdobramentos na execução do debate não se tenham podido tornar objeto de problematização no percurso de implementação do projeto, constituem-se em indício não prescindível para se pensar sobre o lugar da oralidade ou de gêneros orais no ensino de língua portuguesa.

Ora, tanto a oposição que os alunos estabeleceram entre escola versus alunos, quando da leitura e discussão dos textos escritos da coletânea, quanto a conformação dos posicionamentos favorável e contrário nos dois grupos revelam em que medida o ensino da oralidade é suscetível de fazer emergir em sala de aula tensões que ganham corpo, em grande medida, em função das ações ensejadas pelos instrumentos didáticos, senão vejamos: embora no percurso de implementação do projeto de ensino os alunos tenham tido acesso a um conjunto de tópicos de conteúdos relativos ao objeto de ensino debate oral (entre os quais, as noções de persuasão e o modo de organização global e funcionamento do debate), o conjunto de aspectos supostos na polêmica sobre a expulsão de alunos da escola (o tópico de conteúdo aparentemente mais enfatizado) vai se traduzindo, no momento do planejamento e da execução do debate, como um problema aparentemente interindividual, um conflito cuja fonte está na distinção entre garotas e garotos.

A esse propósito, poderíamos dizer que o modo de distribuição dos alunos nos grupos quando do planejamento e da execução do debate impacta pouco seu distanciamento com relação a uma questão que lhes é objetivamente próxima, o que parece produzir efeito sobre como constituem seu estatuto de debatedores e seus posicionamentos com relação à polêmica, no episódio em questão e ao longo do percurso didático.

Desdobramentos didáticos como esses estão no coração do trabalho do professor, e sua emergência em sala de aula indiciam mais do que a eventual limitação do dispositivo didático empregado - da presentificação do tema pela leitura e discussão de textos, passando pela topicalização de conteúdos relativos à organização composicional e ao funcionamento do debate pela reprodução e discussão de vídeos, até o planejamento e a execução do debate. Mais do que isso, indiciam que entre os desafios da mediação didática do processo de construção da opinião na sala 
de aula encontra-se centralmente a dimensão ideológica e política dos processos de tomada de posição constitutivos da produção de gêneros orais argumentativos como o debate, o que corrobora as percepções de BENTES (2011) quando põe em questão a função do ensino da oralidade na construção da civilidade democrática:

Assim, quando defendemos que o eixo do ensino de oralidade deve pressupor a natureza pública e política das práticas orais na escola, estamos necessariamente falando do estabelecimento de diálogos mais constantes entre a comunidade escolar e a sociedade, da promoção de maiores e mais efetivos espaços e tempos de diálogos intramuros da escola: diálogos dos alunos entre si, entre alunos e professores, dos professores entre si, sempre organizados mediados pelo professor e focados nos princípios éticos da igualdade na diferença, da solidariedade e da liberdade de expressão. Sabemos que essa equação, no interior da escola, é de difícil resolução. Mas a produção do conhecimento na escola e toda a cultura dela derivada só vão ser significativos para a maioria dos sujeitos se a agenda dessas "conversas", desses diálogos for organizada em torno da construção de uma ética pública e de um sentimento de cidadania a ser experienciado por cada um dos participantes. (BENTES, p. 51)

Talvez esteja no enfrentamento desse desafio aquilo que a licencianda representa como princípio didático "essencial": "mostrar aos alunos que eles também têm o direito de apresentarem seu ponto de vista, suas ideias, seus valores" (ALS_Oralidade_2014,p. 16).

\section{Considerações finais}

Se o saber sobre linguagem oral na tradição de ensino da língua portuguesa na escola brasileira constitui-se, em grande parte, conforme a finalidade de distinção e conservação tanto do repertório ou capital cultural legítimo quanto das posições sociais legitimadas para transformá-lo em palavra pública, como aparece suposto na concepção de composição oral do professor Julio Nogueira, em que estaria a particularidade do tratamento da oralidade em nossa escola nos dias de hoje, distantes que nos encontramos das técnicas de recitação ou de composição oral praticadas na história do ensino de língua portuguesa?

A hipótese é de que, no processo de elaboração e implementação curricular que se começa a construir a partir dos anos 1980 no Brasil, é o estatuto escolar do saber que se reconfigura - a oralidade deixa de ser 
unicamente o instrumento de ensino de outros componentes curriculares (embora essa função possa se manter suposta), mas o próprio objeto de ensino e de estudo, o conteúdo ou o saber escolar central em jogo. Com esse estatuto renovado, os gêneros orais, em sua relação complexa com a escrita e com outros sistemas semióticos (outras linguagens), como ocorre no caso dos gêneros televisivos e dos gêneros digitais (ROJO, 2017), passam a pressionar a reconfiguração das próprias práticas de ensino e a geração potencial de novas práticas.

A linguagem oral é um locus particularmente instigante para fazer emergir tais práticas, uma vez que ocupa historicamente o posto de prima pobre da linguagem escrita, por excelência a modalidade linguística constituída em meio e fim da instrução escolar (LAHIRE, 2008), na qual se assentam os princípios geradores dos saberes e dos métodos legitimados na escola. Com esse caráter marginal ou periférico, pode-se constituir em um locus potente com base no qual é possível pôr em questão os processos de recepção-produção-edição-distribuição dos produtos culturais na escola.

Mas para isso talvez se possa tomar como imprescindível a conceituação mais incrementada da própria natureza do objeto que se pretende ensinar e da possibilidade de sua modelização didática, sobretudo se considerarmos ser essa última o pressuposto de sua ensinabilidade, como defendem De Pietro; Schneuwly (2006). A esse propósito, vale notar que, embora se tenha delimitado e ensinado um conjunto de tópicos de conteúdo no percurso de implementação dos projetos de ensino, ainda assim se faz economia, por exemplo, da materialidade semiótica oral em que o debate se constitui e o valor que adquire nas práticas sociais de uso da língua. ${ }^{12}$

Por fim, do ponto de vista da formação do futuro professor de língua portuguesa, os registros do relatório de estágio que ilustram a discussão proposta neste estudo trazem indícios (suscetíveis de melhor qualificação pelo recurso a um conjunto mais amplo de dados) de diferentes desafios do ensino da oralidade na aula de língua portuguesa que não se reduzem à delimitação de quais saberes selecionar ou à definição de quais instrumentos didáticos mobilizar (esse é o pressuposto necessário e inevitável), mas que se relacionam sobretudo à finalidade do ensino dos gêneros orais em nossa

\footnotetext{
${ }^{12}$ Em uma profícua reflexão sobre o texto oral na escola, Bentes (2010) postula um conjunto de particularidades da língua oral suscetíveis de subsidiar a tarefa de elaboração didática da oralidade como objeto de ensino.
} 
escola pública: em favor de qual formação da criança e do jovem brasileiros, com vistas à construção de que educação e de que sociedade brasileira (cf. GOMES-SANTOS, 2009; 2017; NONATO, 2018). Parece estar nessa finalidade o desafio radial do trabalho do professor no tratamento da oralidade em sala de aula atualmente.

\section{Agradecimentos}

A pesquisa de que decorre este estudo conta com o apoio do Conselho Nacional de Desenvolvimento Científico e Tecnológico (Bolsa de Produtividade em Pesquisa 310898_2015-3 - Março/2016-Março/2019), a que agradecemos.

\section{Referências}

BENTES, A. C. Linguagem oral no espaço escolar: rediscutindo o lugar das práticas e dos gêneros orais na escola. In: ROJO, R.; RANGEL, E. (Org.). Explorando o ensino: Língua Portuguesa. Brasilia, DF: Ministério da Educação, 2010. p. 15-35.

BENTES, A. C. Oralidade, política e direitos humanos. In: ELIAS, V. M. (Org.). Oralidade, leitura e escrita no ensino de língua portuguesa. São Paulo: Contexto, 2010. p. 41-53.

BOTO, C. A civilização escolar como projeto político e pedagógico da modernidade: cultura em classes, por escrito. Cadernos Cedes, Campinas, v. 23, n. 61, p. 378-397, 2003. DOI: https://doi.org/10.1590/S0101-32622003006100008

BRASIL. Lei $n^{\circ}$ 5.692, de 11 de agosto de 1971. Fixa diretrizes e bases para o ensino de $1^{\circ}$ e $2^{\circ}$ graus e dá outras providências. Diário Oficial da União: seção 1, Brasília, DF, ano 108, p. 6377, 12 ago. 1971.

BRASIL. Parâmetros Curriculares Nacionais: terceiro e quarto ciclos do Ensino Fundamental - Língua Portuguesa. Brasília, DF: Ministério da Educação/Secretaria de Ensino Fundamental, 1998.

BUENO, S. Arte de falar em público. 3. ed. mod. São Paulo: Editorial Presença, 1945. BUNZEN, C. S. A fabricação da disciplina escolar Português. Revista Diálogo Educacional, Curitiba, v. 11, p. 885-911, 2011.

DE PIETRO, J-F.; SCHNEUWLY, B. O modelo didático do gênero: um conceito da engenharia didática. Moara, Belém, ano 13, n. 26, p. 15-52, 2006.

FARIA FILHO, L. M. Representações da escola e do alfabetismo no século XIX. In: GALVÃO, A. M. O.; BATISTA, A. A. G. (Org.). Leitura: práticas, impressos, letramentos. Belo Horizonte: Autêntica, 2005. p. 143-164. 
FIORIN, J. L. Para uma história dos manuais de português: pontos para uma reflexão. Scripta, Belo Horizonte, v. 3, n. 4, p. 151-161, 1999.

GOFFMAN, E. Façons de parler. Paris: Les Éditions de Minuit, 1987.

GOMES-SANTOS, S. N. A escrita nas formas do trabalho docente. Educação e Pesquisa, São Paulo, v. 36, n. 2, p. 445-457, maio/ago. 2010.

GOMES-SANTOS, S. N. A questão do gênero no Brasil: teorização acadêmicocientífica e normatização oficial. 2004. Tese (Doutorado em Linguística) - Instituto de Estudos da Linguagem, Universidade Estadual de Campinas, Campinas, 2004.

GOMES-SANTOS, S. N. Formação inicial e letramento do professor de lingua portuguesa: conceber, implementar e avaliar projetos de ensino. Projeto de Pesquisa (Bolsa PQ-CNPQ Proc. no 310898/2015-3) - Faculdade de Educação, Universidade de São Paulo, São Paulo, 2016-2019.

GOMES-SANTOS, S. N. Modos de apropriação do gênero debate regrado na escola: uma abordagem aplicada. DELTA: Documentação de Estudos em Linguística Teórica e Aplicada, São Paulo, v. 25, n. 1, p. 39-66, 2009. DOI: https://doi. org/10.1590/S0102-44502009000100002

GOMES-SANTOS, S. N. Multissemiose e ensino de língua portuguesa. In: GONÇALVES-SEGUNDO, P. R.; MODOLO, A. D. R.; SOUSA, D. R. de; FERREIRA, F. M.; COAN, G. I.; BRITTO-COSTA, L. F. (Org.). Texto, discurso e multimodalidade: perspectivas atuais. São Paulo: Paulistana, 2017. p. 319-332.

GOMES-SANTOS, S. N.; SEIXAS, C. Gêneros textuais da formação docente inicial: o projeto de ensino de língua portuguesa. Scripta, Belo Horizonte, v. 16, n. 30, p. 151-168, 2012.

LAHIRE, B. La raison scolaire: école e pratiques d'ecriture, entre savoir et pouvoir. Rennes: Presses Universitaires de Rennes, 2008.

MARCUSCHI, L. A. A oralidade e o ensino de língua: uma questão pouco falada. In: DIONÍSIO, A. P.; BEZERRA, M. A. (Org.). O livro didático de português: múltiplos olhares. Rio de Janeiro: Lucerna, 2001. p. 19-34.

NOGUEIRA, J. Composição oral. In: . A linguagem usual e a composição. Rio de Janeiro: Livraria Editora Leite Ribeiro Freitas Bastos \& Cia., 1929. p. 311-322.

NONATO, S. Processos de legitimação da linguagem oral no ensino de língua portuguesa. Cadernos CEDES, Campinas, v. 38, n. 105, p. 222-239, 2018. DOI: https://doi.org/10.1590/cc0101-32622018183601

PERELMAN, C.; OLBRECHTS-TYTECA, L. Tratado da argumentação: a nova retórica. São Paulo: Martins Fontes, 2005. 
PIETRI, E. A constituição do discurso da mudança do ensino de língua materna no Brasil. 2003. Tese (Doutorado em Linguística Aplicada) - Instituto de Estudos da Linguagem, Universidade Estadual de Campinas, Campinas, 2003.

PIETRI, E. Sobre a constituição da disciplina curricular de língua portuguesa. Revista Brasileira de Educaşão, Rio de Janeiro, v. 15, n. 43, p. 70-83, 2010.

RAZZINI, M. P. G. O Espelho da Nação: a Antologia Nacional e o ensino de português e de literatura (1838-1971). 2000. Tese (Doutorado em Teoria Literária) - Instituto de Estudos da Linguagem, Universidade Estadual de Campinas, Campinas, 2000.

ROJO, R. H. R. Gêneros de discurso/texto como objeto de ensino de línguas: um retorno ao trivium? In: SIGNORINI, I. (Org.). Rediscutir texto, gênero e discurso. São Paulo: Parábola, 2008. p. 73-108.

ROJO. R. H. R. Entre plataformas, ODAs e protótipos: novos multiletramentos em tempos de WEB2. The Especialist, São Paulo, v. 38, n. 1, p. 1-20, 2017.

SCHNEUWLY, B. Le travail enseignant. In: SCHNEUWLY, B.; DOLZ, J. (Org.). Des objets enseignés en classe de francais: le travail de l'enseignant sur la rédaction de texts argumentatifs et sur la subordonnée relative. Rennes: Presses Universitaires de Rennes, 2009. p. 29-43.

SCHNEUWLY, B.; DOLZ, J. (Org.). Des objets enseignés en classe de français: le travail de l'enseignant sur la rédaction de texts argumentatifs et sur la subordonnée relative. Rennes: Presses Universitaires de Rennes, 2009.

SILVA, W. R. Escrita do gênero relatório de estágio supervisionado na formação inicial do professor brasileiro. Revista Brasileira de Linguística Aplicada, Belo Horizonte, v. 13, n. 1, p. 171-195, 2013. DOI: https://doi.org/10.1590/S198463982012005000016

SILVA, W. R.; MELO, L. C. Relatório de estágio supervisionado como gênero discursivo mediador da formação do professor de língua materna. Trabalhos em Linguistica Aplicada, Campinas, v. 47, n. 1, p. 131-149, 2008. DOI: https://doi. org/10.1590/S0103-18132008000100008

SOARES, M. Português na escola - história de uma disciplina curricular. In: BAGNO, M. (Org.). Linguistica da Norma. São Paulo: Edições Loyola, 2002. p. 155-177.

Data de submissão: 07/05/2018. Data de aprovação: 12/12/2018. 